\title{
AUTOMATIC EXTERIOR WALL SPRAYING EQUIPMENT: APPLICATION AND EVALUATION
}

\author{
Shinobu Yamazaki \\ Shimizu Corporation \\ No.15-33, Shibaura 4-chome, Minato-ku \\ Tokyo 108, Japan
}

\begin{abstract}
The Multi Coater described in this report is an automatic spraying equipment of suspension type for exterior walls, and is a labor-saving machine developed not aiming for a completely unmanned system, but for use in combination with a conventional painting method using moving scaffold. For lateral movement of the equipment, the rail system at the top of the building is used jointly with moving scaffold on which workers ride. Through application to nuclear power station reactor buildings which are the main objectives of this equipment, it was verified that scatter in coating film thickness is reduced to approximately half of that in case of hand painting. Thus, the total quantity of labor could be reduced by approximately 12 to 20 percent.
\end{abstract}

1. Introduction

Painting had conventionally been performed with the main objectives being improvement of the appearances of buildings and harmony with the surroundings. But in the past several years, there has been increased concern about prolonging the service lives of structures, and in addition to the conventional decorative purpose, a function to protect the structure has come to be demanded of the coating film. As a result, coating materials and coating specifications have become multileveled and multi-faceted, while at the same time, higher levels of coating techniques and quality control regarding coating thickness and adhering strengths than before have been called for. The automatic spray equipment for exterior walls discussed in this paper is a labor-saving machine capable of coping with painting specifications that are becoming increasingly multi-leveled, which was developed aiming for reduction in high-elevation work and for improvement of quality.

\section{Present Situation and Trends Regarding Exterior Wall Coating Work}

Fig.1 shows the composition of a coating membrane in waterproof decorative finishing with a rubber-like elastic coating which has come to be widely used centered on renovation work. The performance will depend on the working conditions during application, but the greatest factor is the uniformity of film thickness, and this is determined by the skill of the spray painter.

While the value added to the coating has been increased, there are on the other had the following problems at the stage of executing work. 
a) Although the number of workers engaged in painting has remained on the same level, there has been a trend for a decrease in the availability of skilled workers to cause concern about maintaining quality of application.

b) While the coating film has become many-layered, the painting operation still relies on manual work to greatly increase manhours and work periods required.

c) Painting work has been performed conventionally at high elevations using scaffolding and moving scaffold involving risk of falling and dropping at all times.

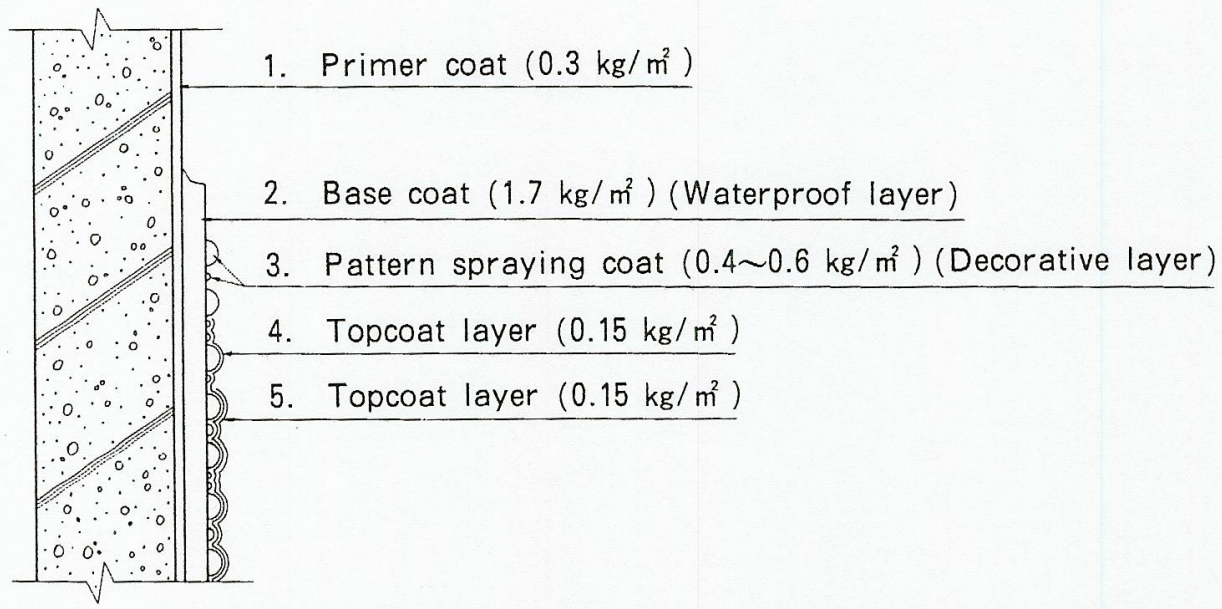

Fig. 1 - Coating composition using waterproof decorating material

\section{Fundamental Concept of Spraying Operations Automation}

In carrying out development, there were many operations which had to be done manually such as parts of spraying operations, masking operations, or substrate treatment before painting. While painting operations involved 3 to 6 spraying processes, which each time would require machinery and men to interchange their positions with good timing, and it was decided to attach a temporary rail system for lateral movement on the building for suspending both automatic spraying equipment and moving scaffold for workers.

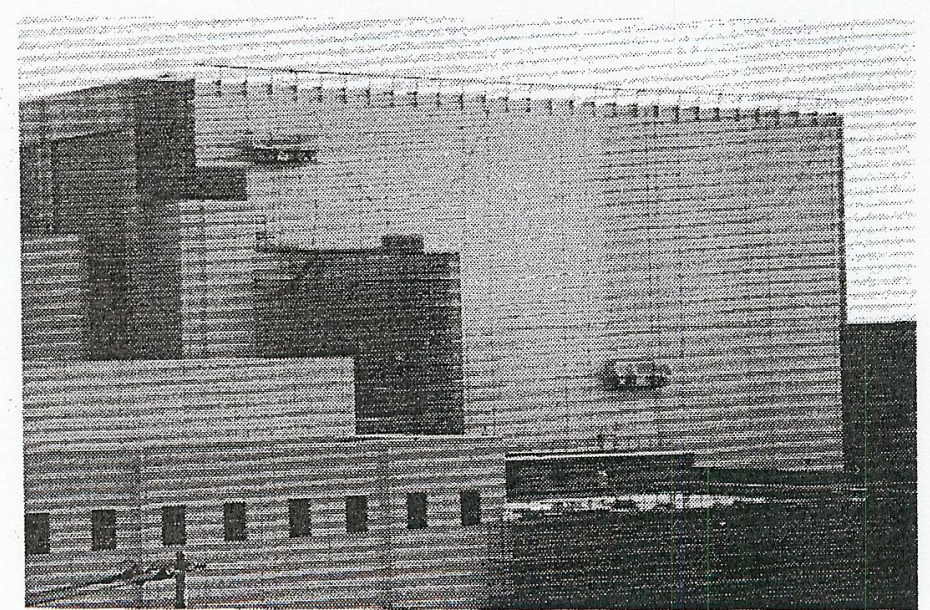

Photo 1 Exterior wall spraying operation using two Multi Coaters 
Such a form of scaffolding combining moving scaffold and lateral movement rail is rational from the standpoint of machine and man mutually augmenting each other, while hereafter, if automatic equipment of suspended type were to be made similarly for substrate treatment and sealing operations, it would be possible for a practical automatic exterior wall working system to be developed.

4. Brief Description of automatic Exterior Wall Spraying Equipment

4-1. Spraying Operation Automation Technology

In the process of development, work was carried out with emphasis on securing reliability of the spraying method and spraying equipment from the point of view of securing quality. The technical problems and solution methods in development of this equipment are briefly described below.

a) Spraying Method for Securing Uniform Film Thickness

As the spraying method, a system basically for spraying in a straight line sideways and going down in stages from top to bottom providing a suitable overlapping width was adopted. For the primer and top coat which are of low viscosity, the method adopted was to spray with a pair of guns, upper and lower, moved horizontally back and forth. For the rubber-like elastic coating material of high viscosity, since it could not be expected for a regular pumpability of high precision to be achieved, and also from the fact that thick spraying had to be done to obtain a film thickness of 0.6 to $1 \mathrm{~mm}$ on drying, two guns as shown in Photo.2 rotating at high speed were moved back and forth for spraying. Using this method, any number of thin films can be sprayed to form a membrane of the required thickness so that a good-quality application with little scatter can be attained.

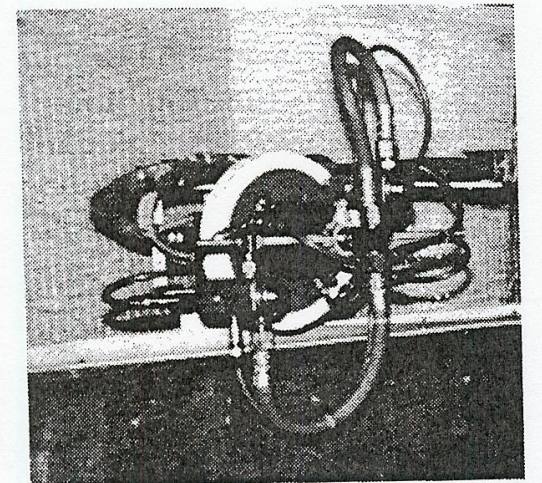

Photo 2 Rotating gun unit

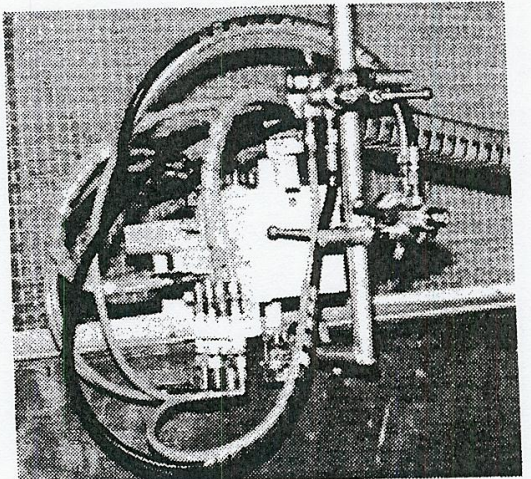

Photo 3 Airless gun unit

b) Stable Atomizing of Coating Material

The uniformity of film thickness is greatly affected by the quantity of coating material ejected and the regularity of the misting pattern from the gun in addition to the method of spraying. Considerations given are, besides eliminating variation in discharge quantity due to pressure loss by mounting the pump on the equipment and providing a filter in the line from coating material hopper to gun, are not using an airless pump which is prone to pulsations, but a combination of snake pump and pneumatic gun for the rubber-like elastic coating material. In addition, the following original measures were provided: 
- Focusing on the fact that the rubber-like elastic coating material is water-based, disturbances of misting patterns caused by deposition and adherence of material at the end of the gun are prevented by moistening the air for atomizing.

- A proper pressure inside the hose is aimed for by providing the pump with an automatic reversal function to preclude spitting at beginning of coating material dischange.

c) Prevention of Flying of Mist

Although application by spraying has good efficiency, flying of mist is often a problem on the other hand. In the case of this equipment, the range of movement of the gun is provided with a vinyl cover to form a spraying booth, and flow-out of suspended mist is suppressed with dust collecting fans and filters attached to the top of the booth.

d) Prevention of Shaking of Equipment

With a suspended type of equipment, there will be cases when the whole unit will shake substantially due to the movements of the equipment itself and to wind. Therefore, this equipment is equipped with wall suction devices of adjustable-length piston-and -cylinder type utilizing an ejector and guide rollers to stabilize posture during spraying.

4-2. Automatic Exterior Wall Spraying equipment(The Multi Coater)

This equipment(The MC), as shown in Fig.2, is suspended from the trolley on the lateral rail by wire ropes and automatically sprays from the top of the building to the bottom through wireless operation by the operator. The operating procedure is to select by switch whichever of the operations out of primer application, base spraying(rubber-like elastic coating material), pattern spraying, and topcoat spraying, after which the wireless control box is employed to move the MC to the location of start of work, and automatic operation is entered by merely pushing the automatic start button.

The MC executes the spraying operation based on operating data such as lateral movement speed of gun, spraying width, and overlap amount (amount of descent) inputted beforehand according to the spraying process selected.

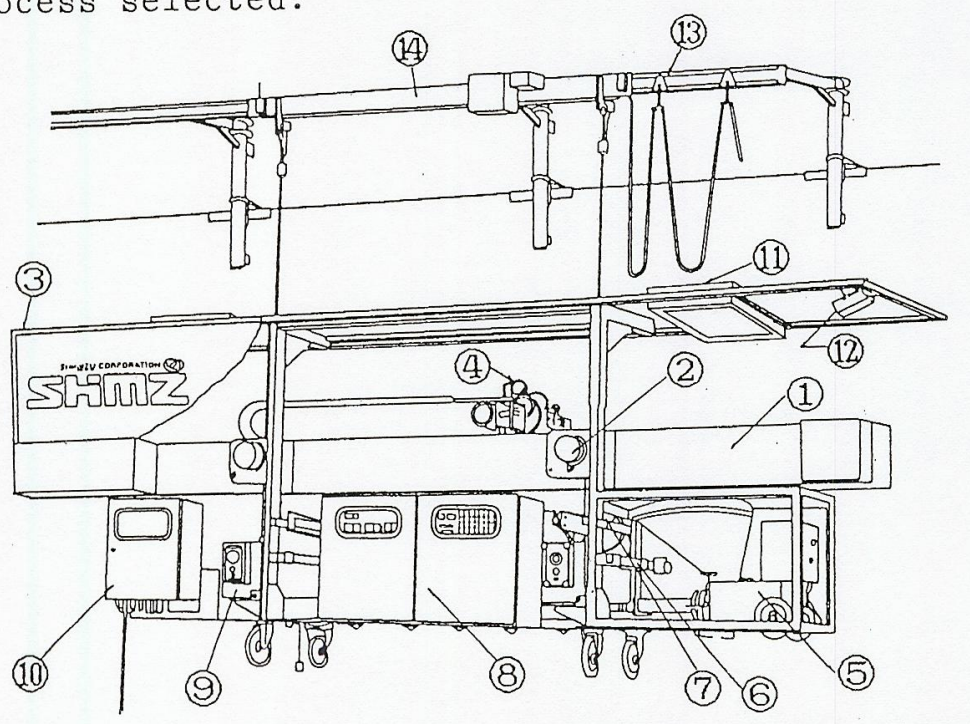

(1) Recipocator

(2) Descent distance sensor

(3) Booth cover

(4) Automatic gun unit

(5) Material pump

(6) Guide roller

(7) Wall suction device

(8) Control panel

(9) Hoisting and lowering winder

(10) Pneumatic control box

(11) Dust collecting fan

(12) TV camera

(13) Lateral-movement rail

(14) Trolley

Fig.2 - Equipment composition of Multi Coater 


\section{Examples of Application and Results}

In the following the effects when using the MC are considered based on the results of application in exterior wall painting work of the nuclear power station turbine building construction project.

a) Object of Application and Automation Ratio

The building which was the object of painting was a turbine building of a height above ground of $34 \mathrm{~m}$, and building area of approximately $6,000 \mathrm{~m}^{2}$, and three sides excepting the east side were coated. However, because the building had various protuberances and recesses, large and small, the surface was divided into parts were lateral-movement rails were installed and the MC was mainly used for application (automated method) and parts where all work was done manually using scaffolding or moving scaffold (conventional method). Even at a surface where coating was done using the MC, there were portions such as the ends of the building and parts around piping which could not be handled by the MC, and the automation ratio in the range of automated method application was 88 percent, the automation ratio for the total coating area of $9,163 \mathrm{~m}^{2}$ being 46.5 percent. Although this cannot necessarily be said to be high, trial calculations have been made showing that the automation ratio can be raised to 95 percent at the automated method application part and 60 percent overall by measures such as 1) changing location of piping, 2) installation of equipment after coating, and 3) increasing the amount of cantilevering outward of the lateral-movement rail.

\section{b) Working Efficiency}

The coating specifications for this project were the same as shown in Fig.1. Two MC were used in executing the work and a wall area of $4,200 \mathrm{~m}^{2}$ was coated by 30 days of actual work. Consequently, the coating capacity in completing the five spraying processes, including appurtenant work such as adjustment of spray guns and clean-up, was approximately $70 \mathrm{~m}^{2} /$ man-unit-day, and was roughly equal to the 3 men to a crew in case of using scaffolding as shown in Table 2. The results of calculating the daily average work composition ratio when using the MC based on application data are shown in Fig. 3. The operating ratio of the automatic machine was 45 percent of the working hours per day of approximately 8 hours. As reasons for this, trouble with the MC at the early stages, unfamiliarity with operation of the MC and the work procedure, and the fact that at parts where the Multi Coater could not cope, augmenting was done by manual means can be cited, and there were cases when waiting periods occurred for the MC However, since there had been cases of the automatic machine operating ratio having reached 68 percent, it is considered possible for resting and waiting times to be shortened through establishment of working criteria, formulation of plans considering learning effect of operator, and securing line balance between automatic machine and personnel, and as shown in the bottom part of the figure it is thought the operating ratio of the automatic machine can be raised to approximately 60 percent. The working efficiency in such case will exceed that of conventional methods and become 100 $\mathrm{m}^{2} / \mathrm{man}$-unit-day . 
Table 1 - Spraying capacity of Multi Coater

\begin{tabular}{c|c|c|c|c|c}
\hline & \multicolumn{5}{|c}{ Spraying step } \\
\cline { 2 - 6 } & $\begin{array}{l}\text { Prime } \\
\text { coat }\end{array}$ & $\begin{array}{l}\text { Base } \\
\text { coat }\end{array}$ & $\begin{array}{l}\text { Pattern } \\
\text { coat }\end{array}$ & $\begin{array}{c}\text { Topcoat } \\
(1 \mathrm{st})\end{array}$ & $\begin{array}{c}\text { Topcoat } \\
\text { (2nd) }\end{array}$ \\
\hline $\begin{array}{c}\text { Quantity coated } \\
{\left[\mathrm{kg} / \mathrm{m}^{2}\right]}\end{array}$ & 0.3 & 1.7 & 0.5 & 0.15 & 0.15 \\
\hline $\begin{array}{c}\text { Spraying capacity } \\
{\left[\mathrm{m}^{2} / \mathrm{Hr}\right]}\end{array}$ & 220 & 80 & 120 & 220 & 220 \\
\hline
\end{tabular}

Table 2 - Comparison of work efficiencies

\begin{tabular}{c|c|c}
\hline & Work crew make-up & Work efficiency \\
\hline $\begin{array}{c}\text { Conventional } \\
\text { method }\end{array}$ & $\begin{array}{c}\text { High elevation } \\
\text { Spraying operater }\end{array}$ & Using assembled scaffolding \\
& 0 & 0
\end{tabular}

\begin{tabular}{|c|c|c|}
\hline & Material supplier & $\begin{array}{l}\text { Using gondola } \\
\qquad 90 \mathrm{~m}^{2} / 3 \text { men-day }\end{array}$ \\
\hline $\begin{array}{l}\text { Automated } \\
\text { method }\end{array}$ & $\begin{array}{c}\text { High elevation } \\
\text { On ground } \\
\text { Material sumplier } \\
\text { cum operator }\end{array}$ & $\begin{array}{l}\text { Actual performance } \\
\qquad 70 \mathrm{~m}^{2} / \text { man-unit-day } \\
\text { Capacity predicted after improvements } \\
\qquad 100 \mathrm{~m}^{2} / \text { man-unit-day }\end{array}$ \\
\hline
\end{tabular}

* The value of work efficiency is the average work efficiency when finishing

to painting specifications involving 5 processes and includes all oprations.

Performanc

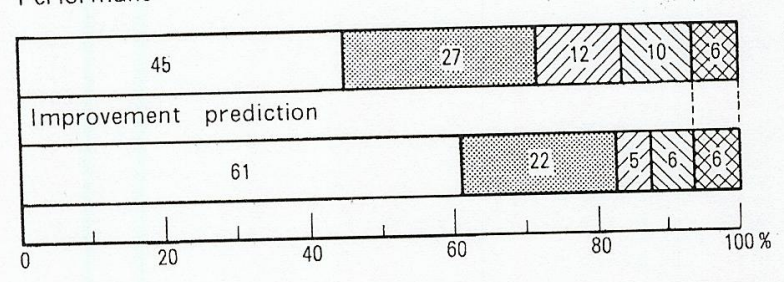

$\mathrm{Fig} \cdot 3$ -

Ratios of component operations

per day when using Multi Coater
(1) $\square$ Operation

- Automatic spraying

L Movement (ascent, lateral movement)

(2) Preparation

$\leftarrow$ Delivery, removal

- Adjustment

- Preparation before starting operation

- Clean-up, washing after operations

- Changeover

(3) एयत Trouble

- Initial trouble with equipment

Operating error

- Poor maintenance

(4) Stand-by

- Error in relay to manual

L Waiting for drying of paint

(5) Other Discussions before operation
Other items 
c) Quantity of Labor for Work Execution and High-Elevation Work

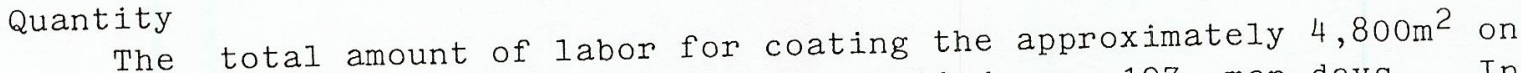
which the automated method was mainly applied was 197 man-days. In Fig. 4, breakdowns of the total quantities of labor compared with the amounts trial calculated for coating of the same part by various conventional methods are shown. The results of calculations using the working efficiencies in case of improving the operating ratios of the automatic machine along with actual records are also given. The following were made clear by these results:

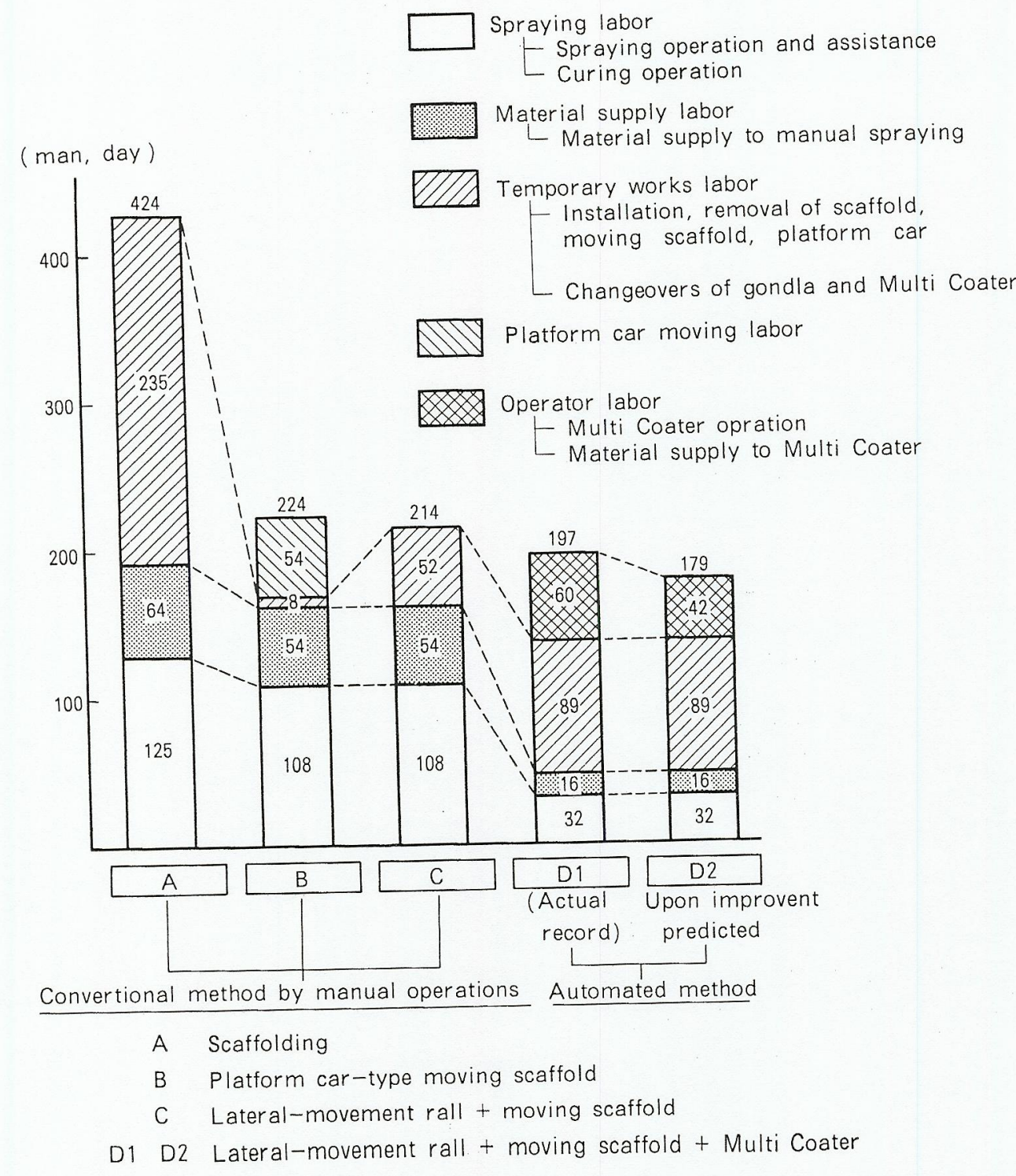

* In trial calculations of total labor quantities the area sprayed was made the same $4,800 \mathrm{~m}^{2}$ as the area to which the automated method was applied at the job site, with conventional methods all carried out manually using the above various scaffoldings. In case of the automated method, the areas worked by Multi Coater and manual oprations were taken to be $4,200 \mathrm{~m}^{2}$ and $600 \mathrm{~m}^{2}$, re-spectively.

Fig. 4 - Total labor quantities in executing work 
1) Compared with the case of using a platform car-type moving scaffold which is a standard type of conventional method, it is possible when using the MC to reduce total labor by 12 percent, and in case of improvement in working efficiency of the automated machine,' 20 percent.

2) With regard to spraying labor requiring painting skills, skilled labor is reduced by 75 and 70 percent, respectively, compared with the cases of using assemble scaffolding and moving scaffold when using the SB Multi coater.

3) Spraying labor in the category of high-elevation work is reduced by 70 to 75 percent to greatly improve safety.

\section{d) Coating Quality}

Exterior wall painting is ordinarily controlled with respect to finished appearance, thickness and uniformity of coating film, and adhering strength. The finished appearance was not inferior compared with painting by manual operations, while adhering strengths were also equal. As for film thickness in base spraying which is the most important for waterproofing, the coefficients of variation were 18.3 percent for manual spraying and 8.6 percent for mechanized spraying for scatter of less than half that in manual operation, and it was confirmed that the MC is effective in improving quality.

6. Conclusion

The technique of automating exterior wall spraying operations presented here is featured by the fact that considerations have been given to make possible smooth mutual supplementation between man and machine by making the movement modes of moving scaffold used by workers and of the automated machine the same. By doing so, waste in temporary facilities and in work execution can be eliminated, and practical effects can be obtained even with only partial automation, while it is also possible to gain an outlook for automation of other operations.

The appropriateness of this thinking was verified through a number of applications. However, programming techniques for standardization of operations and for mixtures of conventional and automated methods have not yet been established at this stage, and reductions in work periods and cost have not been achieved as yet. On the other had, although spraying techniques to be basic in technical aspects had been established, there are many problems still to be resolved, such as strengthening of measures for preventing flying of mist.

Even with the level presently attained, improvement in safety and saving of labor can be looked forward to, and it is intended for application "know how" to be accumulated through increased utilization of the MC, improving productivity of exterior wall painting works.

\section{Acknowledgements}

The authors are deeply indebted to and thank the persons concerned in the Architectural Sections of Fukushima No.2 Nuclear Power Station and Kashiwazaki-Kariba Nuclear Power Station of Tokyo Electric Power Co., Inc. and Hamaoka Nuclear Power Station of Chubu Electric Power Co., Inc. for their understanding and guidance from the stage of testing of the MC and until its introduction in actual projects. 